\title{
PELAKSANAAN SISTEM PENGURUSAN JAMINAN HALAL DI RUMAH-RUMAH SEMBELIHAN AYAM HALAL DAN ISU-ISU BERKAITAN: SATU SOROTAN LITERATUR
}

\section{The Implementation of Halal Assurance Management System in Malaysia's Certified Halal Slaughter Houses and Its Related Issues: A Literature Review}

\author{
Muhammad Mazuan Razaly \\ Master Candidate, Department of Shariah and Law, \\ Academy of Islamic Studies, \\ University of Malaya, 50603 Kuala Lumpur. \\ muhamad_mazuan@siswa.um.edu.my \\ Zalina Zakaria \\ Senior Lecturer, Department of Shariah and Law, \\ Academy of Islamic Studies, \\ University of Malaya, 50603 Kuala Lumpur. \\ zalina_jsu@um.edu.my
}

\begin{abstract}
A continuous halal control through the implementation of Halal Assurance Management System (HAS) needs to be properly executed to ensure that the process meets the halalan toyyiba aspects. The halal processing chain, especially at slaughtering premises, are very vulnerable to inaccuracy. The failure of the industry to meet the halalan toyyiba aspects can adversely affect the quality of the slaughtered products and even more serious, a non-halal slaughter. Hence, the study was conducted to examine the implementation of HAS by the industry and to address the issues related to its implementation. In order to ensure that the gathering of information process is working smoothly, this qualitative study uses three important instruments ie document analysis involving journals and scientific writing, interviews
\end{abstract}


and followed by field observations. The outcome of this study is expected to be the basis for improving the quality of halal regulation management internally and also assisting in the enhancement of halal management at the Jabatan Kemajuan Islam Malaysia (JAKIM) level.

Keywords: Halal Assurance Management System, Halal Slaughtering, Malaysian Halal Certification, Halal Compliance,

\section{PENGENALAN}

Industri sembelihan dalam negara bukan sesuatu yang baru malah telah direkodkan sejak sebelum perang tercetus. Tidak kurang daripada enam buah rumah sembelihan telah dibangunkan pada masa tersebut dan ia semakin berkembang pada hari ini (Ahmad Mustaffa Babjee, 1994: 96). Penghasilan produk sembelihan menumpukan kepada dua industri utama iaitu industri ruminan $^{1}$ dan unggas. ${ }^{2}$ Industri ruminan kebanyakannya dijalankan dalam skala kecil hanya untuk pasaran pengguna sekitar. Ia berbeza dengan industri unggas khususnya ayam, yang mana produknya turut dipasarkan di beberapa negara jiran di samping pasaran tempatan.

Industri sembelihan ayam dalam negara melibatkan pembekal yang memiliki sijil halal dan juga tidak memiliki sijil halal. Tidak dinafikan walau ada sesetengah pengusaha berlumba-lumba untuk mendapatkan sijil halal, ada juga segelintir daripada mereka yang tidak berhasrat untuk mendapatkan sijil halal. ${ }^{3}$ Walau apapun, pengusaha-pengusaha hari ini mempunyai pilihan sama ada untuk memohon sijil halal atau pun sebaliknya. Hal ini ekoran permohonan sijil halal adalah bersifat sukarela dan tidak diwajibkan. Bagi

1 Ruminan ialah haiwan yang mempunyai empat komponen perut iaitu omasum, abomasum, rumen dan retikulum. Haiwan ini memuntahkan semula makanan yang kemudian dikunyah semula untuk dicerna dengan lebih efisien. Ia terdiri daripada ternakan lembu pedaging, lembu tenusu, kerbau, kambing pedaging, bebiri dan kambing tenusu. Department of Islamic Development Malaysia, The Malaysian Protocol For The Halal Meat And Poultry Productions (Department of Islamic Development Malaysia, n.d.),8.

2 Unggas bermaksud spesis burung terdiri daripada ternakan ayam, itik, angsa, ayam belanda, merpati tanpa mengira umur dan jantina. Department of Islamic Development Malaysia, The Malaysian Protocol For The Halal Meat And Poultry Productions (Department of Islamic Development Malaysia, n.d.),7.

3 Muhammad Hawari Hassan (Penolong Pengarah Kanan, Bahagian Hub Halal JAKIM), dalam temu bual bersama penulis pada 23 Mei 2017. 
mereka yang membuat pilihan untuk mendapatkan sijil halal, pastinya mereka akan berusaha sedaya upaya untuk memenuhi kehendak serta prosedur yang ditetapkan. Permohonan sijil halal ini boleh dilakukan melalui pihak JAKIM, Jabatan Agama Islam Negeri (JAIN) atau Majlis Agama Islam Negeri (MAIN). Hanya tiga agensi ini sahaja yang boleh mengeluarkan sijil halal. Pensijilan halal boleh dilakukan mengikut lokasi premis beroperasi. Bagi premis sembelihan yang berada di sekitar Lembah Klang, permohonan sijil halal boleh dibuat melalui pihak JAKIM. Manakala bagi premis di luar Lembah Klang, permohonan boleh dibuat melalui Jabatan Agama Islam negeri masingmasing.

\section{PENSIJILAN HALAL RUMAH SEMBELIHAN AYAM}

Pensijilan halal khususnya rumah sembelihan adalah satu proses bagi memperakui serta mengesahkan kehalalan produk sembelihan yang dihasilkan. Proses ini dijalankan bagi mengesahkan produk yang dikeluarkan telah memenuhi kehendak jaminan kualiti, perundangan berkaitan kualiti yang ditetapkan, serta syarat-syarat minimum prestasi selain daripada aspek halal (Zalina Zakaria, 2015: 39-50). Pensijilan halal rumah sembelihan adalah salah satu antara tujuh skim pensijilan yang dibuka kepada pengusaha produk sembelihan dalam negara untuk mendapat Sijil Pengesahan Halal Malaysia. ${ }^{4}$ Pensijilan halal rumah sembelihan dinilai di bawah kategori produk makanan dan turut menggunakan standard MS 1500:2009 Halal Food-Production, Preparation, Handling and Storage-General Guidelines (2 Revision).

Pensijilan halal rumah sembelihan ini terbahagi kepada tiga kategori, iaitu kecil, sederhana dan besar (JAKIM, 2015: 40-41). Pembahagian kategori ini berasaskan kepada jumlah sembelihan harian. Yuran permohonan sijil halal juga akan bergantung kepada kapasiti sembelihan sesebuah premis sembelihan. Kategori kecil adalah industri sembelihan yang mana hasil sembelihannya berjumlah dari seekor hingga 2,999 ekor ayam sehari. Bagi kategori sederhana pula, bilangan ayam sembelihan adalah tidak melebihi 10,000 ekor sehari. Kategori ketiga adalah kategori besar yang mana hasil sembelihan harian adalah melebihi 10,000 ekor bagi ayam. Berikut merupakan perincian setiap kategori yang dinyatakan di atas (Ibid: 69):

$4 \quad$ Sijil Pengesahan Halal Malaysia adalah dokumen rasmi yang menyatakan status halal bagi semua produk dan/ atau perkhidmatan berdasarkan kepada skim Pensijilan Halal Malaysia yang dikeluarkan oleh pihak berkuasa berwibawa. Lihat Jabatan Kemajuan Islam Malaysia, Manual Prosedur Pensijilan Halal Malaysia (Semakan Ketiga) 2014 (2015),14. 
Jadual 1: Pembahagian Kategori bagi Rumah Sembelihan

\begin{tabular}{ccccc}
\hline SKIM & \multicolumn{4}{c}{ KATEGORI } \\
\hline \multirow{2}{*}{$\begin{array}{c}\text { Rumah } \\
\text { Sembelihan }\end{array}$} & Saiz Premis & $\begin{array}{c}\text { Jenis } \\
\text { Haiwan }\end{array}$ & $\begin{array}{c}\text { Pengeluaran } \\
\text { Harian }\end{array}$ & $\begin{array}{c}\text { Kadar Yuran } \\
\text { Setahun (RM) }\end{array}$ \\
\cline { 2 - 4 } & Secil & $1-2,999$ ekor ayam & 100 \\
& Besar & Melebihi 10,000 ekor ayam & 700 \\
\hline
\end{tabular}

Sumber: Manual Prosedur Pensijilan Halal Malaysia (semakan ketiga) 2014.

Sijil halal ini diberikan kepada tempat atau premis sembelihan yang dikhususkan untuk menyembelih dan memproses binatang secara komersial berpandukan kepada syarat-syarat permohonan yang ditetapkan (Ibid: 13). Sekiranya premis sembelihan turut memproses produk hasilan daripada sembelihan yang dijalankan, pengusaha syarikat tersebut perlu mendapatkan dua skim pensijilan, iaitu pensijilan halal untuk produk dan juga rumah sembelihan. Setiap pengusaha rumah sembelihan yang ingin memohon sijil halal juga hendaklah memastikan mereka memenuhi terma dan syarat-syarat serta keperluan khusus bagi pensijilan halal rumah sembelihan yang ditetapkan.

Sehingga Jun 2017, pemegang sijil halal rumah sembelihan mencecah sejumlah 124 syarikat secara keseluruhannya di seluruh Malaysia. Berikut merupakan perincian pemegang sijil halal bagi rumah sembelihan seperti dinyatakan di atas:

Jadual 2: Pemegang Sijil Halal Rumah Sembelihan di Malaysia

\begin{tabular}{ccccc}
\hline & \multicolumn{5}{c}{ KATEGORI INDUSTRI } \\
\hline NEGERI & KECIL & $\begin{array}{c}\text { KECIL } \\
\text { SEDERHANA }\end{array}$ & $\begin{array}{c}\text { MULTI } \\
\text { NASIONAL }\end{array}$ & JUMLAH \\
\hline JOHOR & 2 & 4 & 8 & 14 \\
KEDAH & 5 & 3 & 1 & 9 \\
KELANTAN & 2 & 1 & 1 & 4 \\
MELAKA & 3 & 2 & 2 & 7 \\
NEGERI & 4 & 2 & 2 & 8 \\
SEMBILAN & & 2 & 1 & 11 \\
PAHANG & 8 & 4 & 2 & 9 \\
P. PINANG & 3 & 5 & 3 & 12 \\
PERAK & 4 & - & - & 2 \\
PERLIS & 2 & 4 & - & 8 \\
SELANGOR & 4 & & &
\end{tabular}




\begin{tabular}{ccccc} 
TERENGGANU & 1 & 2 & - & 3 \\
SABAH & 4 & 7 & - & 11 \\
SARAWAK & 9 & 5 & 1 & 15 \\
JAKIM & 4 & 4 & 3 & 11 \\
\hline JUMLAH & 55 & 45 & 24 & 124 \\
\hline
\end{tabular}

Sumber: Bahagian Hab Halal JAKIM

Data di atas menunjukkan pemegang sijil halal rumah sembelihan yang paling banyak dalam negara adalah pemegang sijil halal kategori kecil yang jumlahnya sebanyak 55 buah syarikat. Seterusnya diikuti oleh kategori sederhana, iaitu sebanyak 45 buah syarikat dan yang paling sedikit adalah kategori besar, iaitu 24 buah syarikat. Dari sudut pemegang sijil halal mengikut negeri, Sarawak merupakan negeri terbanyak yang mempunyai pemegang sijil halal iaitu sebanyak 15 buah syarikat, diikuti oleh Johor dengan jumlah sebanyak 14 buah syarikat dan yang ketiga terbanyak adalah negeri Perak iaitu 12 buah syarikat. Bilangan pemegang sijil halal ini diasaskan kepada beberapa faktor, antaranya peningkatan permintaan terhadap ayam halal dalam kalangan pengguna di sesebuah negeri. ${ }^{5}$ Hal ini disebabkan oleh peningkatan penguatkuasaan terhadap penyalahgunaan logo halal oleh pihak JAKIM dan juga JAIN. ${ }^{6}$

Jumlah di atas pada asasnya bertambah dan berkurang dari masa ke masa bergantung pada tarikh pengeluaran sijil halal dan tarikh tempoh tamat sijil halal. Daripada jumlah pemegang sijil halal di atas, hanya 69 buah syarikat sahaja yang wajib melaksanakan HAS iaitu dari kategori sederhana dan besar selari dengan ketetapan Manual Prosedur Pensijilan Halal Malaysia. Dua kategori ini perlu membangun serta melaksanakan HAS dalam premis masing-masing bagi membantu proses pengawalan dalaman yang dilakukan. Sekiranya terdapat syarikat daripada kategori di atas gagal melaksanakannya, notis ketidakakuran boleh dikeluarkan oleh pihak JAKIM atau JAIN semasa lawatan pengauditan atau pemantauan dilakukan.

5 Mohd Amri Abdullah (Penolong Pengarah Kanan, Bahagian Hub Halal JAKIM), dalam temu bual bersama penulis pada 27 Januari 2018.

6 Asmawaty@Siti Asmah Ahmad (Ketua Unit Persijilan, Bahagian Pengurusan Halal, Jabatan Agama Islam Sarawak), dalam temu bual bersama penulis pada 29 Januari 2018. 


\section{METODOLOGI KAJIAN}

Bagi menilai pelaksanaan Sistem Pengurusan Jaminan Halal, tiga metode utama telah dipilih dengan menggunakan pendekatan kualitatif. Tiga metode utama tersebut adalah analisis dokumen, temu bual serta observasi.

\section{Metode Analisis Dokumen}

Kajian dijalankan dengan merujuk kepada sumber primer dan juga sumber sekunder. Sumber primer yang akan dirujuk adalah seperti Manual Prosedur Pensijilan Halal Malaysia, Garis Panduan Pelaksanaan HAS dan beberapa dokumen yang lain. Manakala rujukan terhadap sumber sekunder pula akan meneliti artikel-artikel jurnal serta penulisan yang berkaitan dengan sembelihan dan juga pelaksanaan HAS.

\section{Metode Temu bual}

Temu bual secara berstruktur akan dilakukan untuk menjawab persoalan kajian bagaimana pihak industri mengaplikasikan HAS atau secara khususnya menentukan serta mengawal titik kritikal halal. ${ }^{7}$ Oleh itu beberapa pihak telah dikenalpasti untuk dijalankan temu bual. Pihak-pihak tersebut adalah pihak JAKIM, Jabatan Perkhidmatan Veterinars serta pihak industri rumah sembelihan.

\section{Metode Observasi}

Pemerhatian serta pengamatan dilakukan terhadap pelaksanaan HAS khususnya pelaksanaan enam prinsip HAS dalam kawasan pemprosesan. Pemerhatian ini dilakukan bagi memperkuatkan lagi dapatan temu bual serta memastikan hasil kajian diperolehi dengan tepat. Proses ini dilakukan dari seawal penerimaan bekalan sehingga produk selesai dihasilkan. Ia dilakukan sejurus selepas sesi temu bual bersama pihak industri.

Titik kritikal halal adalah keseluruhan rantaian pemprosesan halal yang jika dikenal pasti, dikawal dan dipantau akan dapat menghapuskan sebarang kemungkinan berlakunya ketidakakuran halal. Halal Hub Division, Guidelines for Halal Assurance Management System of Malaysian Halal Certification, 5. 


\section{SOROTAN KAJIAN LEPAS}

Setelah melakukan beberapa pemerhatian dan tinjauan terhadap sumbersumber yang diperoleh, beberapa tema telah ditetapkan. Tema-tema tersebut bagi memastikan kajian yang dilakukan bakal memenuhi kelompongan penulisan yang sedia ada terhadap pelaksanaan Sistem Pengurusan Jaminan Halal di rumah sembelihan. Oleh itu, sorotan kajian lepas dibahagikan kepada empat tema, iaitu sembelihan halal, pengaturan dan pematuhan halal, sistem jaminan halal dan isu serta cabaran dalam pensijilan halal.

\section{Sembelihan Halal}

Realiti pada hari ini, permintaan terhadap produk halal antaranya daging halal semakin meningkat lebih-lebih lagi dalam kalangan pengguna Muslim. Senario ini tidak hanya berlaku di Malaysia, malah ia merupakan suatu fenomena global dan turut berlaku di negara-negara lain. Peningkatan yang tinggi ini memerlukan bantuan teknologi untuk membantu menghasilkan produk yang banyak dalam masa yang terhad. Beberapa pendekatan baru telah diperkenalkan antaranya seperti mechanical slaughtering, ${ }^{8}$ proses pelalian melalui kaedah stunning dan juga proses mempercepatkan pendarahan melalui kaedah thorasic sticking. ${ }^{9}$ Walau apapun pendekatan yang digunakan, proses tersebut perlu menepati kehendak Syarak. Satu kajian telah dijalankan oleh Suhaimi Abd Rahman et al. (2014: 11-17) yang menyatakan bahawa penyembelihan haiwan kini melibatkan perubahan dalam kaedah yang telah digunakan. Kaedah tradisional telah ditukar kepada teknik moden. Perubahan ini dianggap sebagai satu keperluan bagi menampung permintaan yang tinggi dalam kalangan pengguna Islam untuk mendapatkan daging halal. Kajian

$8 \quad$ Mechanical slaughtering adalah satu proses sembelihan yang menggunakan mesin khas. Penyembelih hanya bertanggungjawab memetik suis untuk menghidupkan mesin pisau mekanikal. Melalui proses ini, ayam-ayam yang telah digantung dan telah dikenakan stunning akan bergerak melalui pisau tajam yang berpusing dan mengenai lehernya. Lihat Jafri Abdullah, Suhaimi Ab Rahman \& Zaidah Mohd Noor (2011), "Sembelihan Halal dalam Industri Makanan Halal," dalam Pengurusan Produk Halal di Malaysia, ed. Suhaimi Ab Rahman \& Jafri Abdullah. Serdang: Penerbit Universiti Putra Malaysia, 26-50.

$9 \quad$ Thorasic sticking adalah prosedur tambahan yang dilakukan ke atas haiwan selepas sembelihan. Sebaik sahaja sembelihan halal dilakukan, tikaman dilakukan di bahagian berdekatan dengan jantung dengan memutuskan bicarotid trunk dengan tujuan untuk mempercepatkan aliran darah dan mempercepatkan kematian haiwan tersebut. Lihat Jafri Abdullah, Suhaimi Ab Rahman \& Zaidah Mohd Noor (2011: 26-50). 
telah menunjukkan bahawa 'urf dianggap sebagai instrumen yang amat sesuai dalam menentukan hukum terhadap amalan penyembelihan haiwan baru ini.

Terdapat juga kajian berhubung penggunaan teknologi moden dalam sembelihan. Antaranya kajian berhubung kesan penggunaan kaedah stunning. Sepertimana yang dijelaskan di atas, stunning mula digunakan bagi menggantikan kaedah tradisional. Ia tidak hanya mampu memenuhi keperluan serta permintaan yang tinggi dalam kalangan pengguna. Malah ia mampu memberi sumbangan yang besar pada industri. Khadijah et al. (2012: 4-5), melalui kajiannya menyatakan sembelihan menggunakan proses stunning mampu mengawal stress haiwan yang ingin disembelih dan ia menyumbang kepada penghasilan daging yang berkualiti (Ibid). Selain itu, terdapat juga kajian lain yang dilakukan berkait dengan kualiti ayam yang dihasilkan. Kajian ini memfokuskan tentang pengurusan proses sembelihan di sesebuah premis sembelihan. Menurut M. Petracci et al. (2010: 17-26), pengurusan ayam sebelum dan semasa proses sembelihan termasuklah stunning adalah antara perkara yang memberi kesan pada kualiti ayam sembelihan (Ibid). Kajian yang dijalankan memberi cadangan agar proses pengurusan ayam sebelum dan semasa sembelihan perlu dilakukan dengan sebaik mungkin bagi mendapatkan kualiti ayam sembelihan yang baik.

Kajian turut dijalankan berhubung sembelihan, namun kali ini merujuk kepada premis sembelihan yang disahkan halal. Antaranya ialah hasil kajian oleh Mohd. Nazri Abdul Rahman dan Sharifudin Md. Shaarani (2012: 895918) yang secara khusus dilakukan terhadap pihak Jawatankuasa Makanan dan Bahan Gunaan Islam (MGI) Negeri Sabah dan Rumah Sembelihan Halal Negeri Sabah. Kajian tersebut mencadangkan beberapa penambahbaikan antaranya perlu kepada penekanan mewujudkan jawatankuasa halal dalaman di rumah sembelihan. Kajian ini juga mencadangkan agar bilangan penyembelih dan pemeriksa halal diletakkan bersesuaian dengan bilangan sembelihan yang dijalankan. Di samping dua cadangan di atas, turut dicadangkan agar kawalan halal dilakukan secara berterusan pada setiap titik kawalan kritikal yang terdedah kepada ketidakakuran pematuhan halal. Pengawalan ini dilihat sangat penting bagi memastikan produk yang dihasilkan benar-benar halal dan dapat ia mampu memenuhi permintaan daging halal dalam kalangan pengguna.

Tidak kurang juga, terdapat kajian yang dijalankan terhadap persepsi pengguna dan permintaan terhadap produk daging halal. Menurut pandangan Marco Tieman et al. (2013: 1112-1129) sepertimana dalam kajian mereka menyatakan bahawa permintaan pengguna terhadap daging halal kini sangat tinggi. Permintaan tersebut terbukti apabila pengguna sanggup mencari dan membayar dengan harga yang lebih tinggi untuk mendapatkan daging yang 
halal. Hasil kajian di atas turut disokong oleh Syed Ghazaly Alquds (2014: 167-178) melalui kajiannya yang menyatakan senario yang sama berlaku dalam kalangan pengguna ekoran kesedaran pengguna dalam mendapatkan daging halal.

Kajian-kajian yang dijalankan terhadap premis atau sembelihan halal kebanyakannya memfokuskan kepada penggunaan kaedah moden dalam proses sembelihan, sama ada dari sudut hukum ataupun kualiti hasilnya. Kajian sedia ada juga banyak memfokuskan terhadap kesedaran serta persepsi pengguna terhadap daging halal. Namun, kajian terhadap proses sembelihan khususnya berkaitan dengan pematuhan halal masih kurang dilakukan, lebihlebih lagi berkenaan pematuhan halal melalui pelaksanaan HAS. Justeru, kajian ini bakal menjadi platform dalam memenuhi kelompongan kajian berasaskan produk sembelihan.

\section{Pengaturan dan Pematuhan Halal}

Pensijilan halal tidak hanya terhenti dengan kebenaran menggunakan logo halal. Premis yang telah mendapat sijil halal ini perlu dilawati secara berkala. Tidak dinafikan bahawa terdapat industri yang benar-benar mematuhi kehendak piawaian halal. Tidak kurang juga ada sebilangan kecil yang mengambil sikap acuh tidak acuh dalam pengawalan halal sehingga menyumbang kepada berlakunya ketidakakuran dalam sesebuah industri. Penemuan ketidakakuran serta isu-isu pemegang sijil halal yang tiada kesudahan mendorong kajian dilakukan dalam aspek piawaian dan pengawalan halal. Menurut kajian Mohd Al'Ikhsan Ghazali dan Siti Salwa Md. Sawari (2015: 15-20), integriti individu yang terdiri daripada pekerja, pengusaha atau pengurus yang terlibat dalam mematuhi standard yang ditetapkan adalah diragui. Ada di antara pengusaha makanan yang tidak lagi mengamalkan piawaian kualiti makanan yang ditetapkan setelah produk mereka memperolehi pengiktirafan halal daripada JAKIM. Perkara ini perlu diberi perhatian yang serius oleh pihak JAKIM/JAIN dan MAIN. Pemantauan yang berterusan perlu dijalankan bagi memastikan pengawalan halal dilakukan sepanjang masa.

Malaysia dikenali sebagai salah sebuah negara yang terkehadapan dalam pengaturan, penguatkuasaan dan pemantauan berkaitan halal (Zalina Zakaria dan Siti Zubaidah Ismail, 2015: 189-216). Logo halal yang dikeluarkan oleh JAKIM selaku badan pensijilan halal Malaysia juga memiliki reputasi yang dikenali di peringkat antarabangsa. Bagi memastikan reputasi negara sentiasa dijaga, pengaturan serta penguatkuasaan halal perlu diperketat dan diperkuatkan. Pendekatan pemerkasaan undang-undang ini memerlukan 
penglibatan semua pihak bermula daripada pengguna sehinggalah kepada pihak badan pensijilan halal.

Terdapat beberapa kajian berhubung aspek undang-undang serta piawaian halal yang telah dilakukan. Antaranya kajian Ahmad Hidayat Buang dan Zulzaidi Mahmod (2012: 271-288) berhubung cabaran terkini industri halal di Malaysia. Sehingga hari ini, Malaysia tidak mempunyai Akta Halal yang terpakai ke seluruh negara untuk memberi kuasa secara terus kepada pihak agensi kerajaan pusat seperti JAKIM. Kuasa secara terus tersebut amatlah penting bagi memantau dan mengambil tindakan penguatkuasaan undang undang berkaitan halal. Di samping itu, kajian yang sama turut mendapati bahawa Akta Perihal Dagangan (APD) 2011 memperuntukkan kuasa memantau dan menguatkuasakan undang-undang berkaitan penggunaan logo halal adalah terletak di bawah Kementerian Perdagangan Dalam Negeri, Koperasi dan Kepenggunaan (KPDNKK). Namun, JAKIM telah diperturunkan kuasa melalui perlantikan sebagai Penolong Perihal Dagangan untuk menguatkuasakan akta tersebut.

Zalina Zakaria dan Siti Zubaidah Ismail antara pengkaji lain yang turut mengkaji mengenai perkembangan pengaturan halal menerusi APD 2011 di Malaysia (2015: 189-216). Kajian dibuat ke atas APD 1972 dan APD 2011 yang telah dihapuskan. Menurut kajian ini, penggubalan APD 2011 bukan sekadar tentang perundangan berkaitan halal, tetapi turut melibatkan penambahbaikan perundangan berkaitan harta intelek, halal, iklan penalti kesalahan dan aspek penguatkuasaan berbanding APD 1972 terdahulu. Selain itu, kadar penalti yang dikenakan terhadap pesalah melalui APD 2011 merupakan penalti yang tinggi jika dibandingkan dengan kesalahan pihak pengeluar yang menyalahgunakan logo halal kepada pengguna. Menurut kajiannya juga, penyeragaman logo halal yang terdapat dalam APD 2011 memudahkan proses pemantauan dan penguatkuasaan halal berbanding APD 1972 yang masih membenarkan pihak lain untuk membuat pensijilan halal.

Selain itu, Mustafa 'Afifi Ab. Halim dan Azlin Alisa Ahmad (2014: 9-14) turut menjalankan kajian berhubung aspek perundangan terhadap pihak pengurusan halal Jabatan Agama Islam Selangor dan Jabatan Agama Islam Negeri Kelantan. Kajian tersebut dijalankan untuk mengkaji aspek perlindungan ke atas pengguna dan penguatkuasaan undang-undang berkaitan dengan halal yang telah dilaksanakan oleh kedua-dua jabatan terbabit. Kajian mendapati bahawa terdapat beberapa penambahbaikan yang perlu dilakukan. Antara penambahbaikan tersebut ialah JAKIM dan MAIN perlu menyediakan kursus serta latihan berhubung penyiasatan dan mempergiatkan kempen bagi meningkatkan kesedaran pengguna terhadap produk halal. Di samping itu, 
kajian yang dijalankan turut memberikan cadangan yang sama sepertimana kajian Ahmad Hidayat Buang dan Zulzaidi Mahmod mengenai perlunya diwujudkan undang-undang halal yang khusus. Kajian yang dijalankan oleh Ahmad Hidayat Buang dan Zulzaidi Mahmod (2012: 271-288) turut mencadangkan beberapa pendekatan bagi memastikan hak-hak pengguna dijaga. Antara cadangan yang diberikan ialah pendedahan dan latihan mengenai penyiasatan serta pendakwaan kepada kakitangan JAKIM. JAKIM juga dicadangkan untuk memperluaskan kempen kesedaran untuk membuat aduan mengenai salah laku halal serta mempertingkatkan kesedaran pengguna tentang halal. Kesemua cadangan ini penting bagi menjaga hak-hak pengguna serta kehalalan produk yang dihasilkan.

Kajian yang dijalankan oleh Mohd Al'Ikhsan Ghazali \& Siti Salwa Md. Sawari (2015: 56-61) meneliti kedudukan standard piawaian halal Malaysia daripada sudut perundangan, di samping mengkaji kelebihan dan kekurangannya. Kajian ini menunjukkan bahawa perundangan halal disusun dengan susunan yang kurang sistematik kerana tercatat dalam seksyen perundangan yang berbeza, iaitu Akta Makanan 1983, Akta Perihal Dagangan 1972 dan Akta Perlindungan Pengguna 1999. Kajian ini merumuskan bahawa standard piawaian halal Malaysia telah dilaksanakan secara menyeluruh dan mampu membantu pihak penguasa memantau produk halal di Malaysia. Di sebalik kelebihan standard yang sedia ada, terdapat juga beberapa kelemahan yang dikaitkan dengan jaminan kualiti halal yang berlaku sehingga ke hari ini. Kelemahan ini tidak seharusnya dibiarkan berterusan kerana ia secara tidak langsung memberi kesan negatif kepada Malaysia dalam membangunkan hab halal.

Kebanyakan kajian yang dilakukan terhadap undang-undang atau standard halal adalah dengan melihat peruntukan dan isi kandungan undang-undang tersebut. Namun, kajian berhubung pematuhan serta pemakaian terhadap undang-undang atau standard halal itu sendiri masih tidak banyak dilakukan. Begitu juga dengan kajian berhubung pemakaian garis panduan HAS dalam pelaksanaan HAS. HAS masih di peringkat permulaan dan baru sahaja diperkenalkan. Semestinya kajian berkaitan tidak banyak lagi dilakukan. Justeru, kajian kali ini akan menumpukan pada pemakaian serta pematuhan terhadap pelaksanaan garis panduan HAS yang dikeluarkan oleh pihak JAKIM.

\section{Sistem Jaminan Halal}

HAS merupakan satu sistem yang baru diperkenalkan dalam Pensijilan Halal Malaysia. Sistem yang diperkenalkan ini memerlukan penglibatan serta tanggungjawab secara bersama dalam sesebuah industri. Di Malaysia, 
peningkatan pemegang sijil halal membataskan kekerapan pemantauan serta pengawalan oleh pihak JAKIM dan JAIN. Kesukaran ini menuntut satu pendekatan lain yang dapat membantu aspek pengawalan di peringkat industri. Justeru, amat bertepatanlah sistem ini sekiranya diperkenalkan. Pelaksanaan sistem ini masih di peringkat awal dan masih belum terdapat kajian dijalankan berkaitan dengannya. Walau bagaimanapun, terdapat beberapa kajian yang menyentuh aspek pelaksanaan sistem ini. Antaranya ialah kajian oleh Muhamad Haziq Hasan et al. (2014: 1553-1556) berkaitan pelaksanaan sistem jaminan halal terhadap pengusaha makanan di Melaka. Kajian tersebut dilakukan terhadap 39 pengusaha makanan yang memiliki Sijil Pengesahan Halal Malaysia. Kajian tersebut mendapati bahawa pengusaha makanan ini telah melakukan pengawalan halal, akan tetapi pelaksanaannya tidak secara menyeluruh. Penumpuan pengusaha hanya diberikan kepada beberapa elemen sahaja seperti dokumentasi, kebersihan serta kualiti makanan, namun tidak mewujudkan jawatankuasa halal dalaman. Seperti yang termaktub dalam Manual Prosedur Pensijilan Halal Malaysia (MPPHM), hanya industri kecil sederhana dan multinasional sahaja yang perlu mewujudkan jawatankuasa halal dalaman (JAKIM, Manual Prosedur Persijilan Halal Malaysia). Arahan pelaksanaan ini tidak melibatkan industri kecil. Namun, cadangan bagi mewujudkan jawatankuasa halal dalaman oleh pengkaji di atas ke atas premis makanan yang kebanyakannya dari industri kecil adalah kurang sesuai. Ia ekoran kekangan jumlah kakitangan yag dilantik bekerja. Pelantikan eksekutif halal atau supervisor halal adalah dirasakan sudah memadai bagi premis makanan tersebut. Namun, jika cadangan tersebut terhadap premis makanan dari syarikat kategori sederhana, besar atau francais, ia adalah sesuai dan perlu untuk ditubuhkan.

Dalam pelaksanaan sistem ini, peranan utama perlu dimainkan oleh eksekutif halal yang bertindak sebagai pengawal di peringkat industri. Bagi menilai keberkesanan pelaksanaan tugas eksekutif halal di peringkat industri, kajian turut dijalankan oleh Muhamad Haziq Hassan et al. (2015: 57-66) yang memfokuskan penelitian terhadap pemahaman serta pelaksanaan sistem jaminan halal dalam kalangan eksekutif halal. Kajian mensasarkan premis sama yang mana respondennya adalah seramai 39 orang eksekutif halal. Hasil kajian mendapati eksekutif halal ini hanya memahami dan melaksanakan HAS mengikut kefahaman mereka sendiri dan tidak menumpukan kepada beberapa elemen yang digariskan dalam pelaksanaan Sistem Pengurusan Jaminan Halal. Pengkaji tersebut juga mencadangkan agar latihan dan pendedahan perlu diberikan kepada eksekutif halal yang dilantik bagi memastikan pelaksanaan HAS dilaksanakan mengikut kehendak yang sebenar. 
Pelaksanaan Sistem Jaminan Halal ini dilihat amat penting kepada semua industri halal bukan hanya di Malaysia, malah di seluruh dunia. Bagi memenuhi keperluan halal global, HAS dilihat sebagai nilai tambah bagi meningkatkan keyakinan pengguna untuk mendapatkan produk halal. Ceranic dan N. Bozinovic (2009: 261-266) dalam penulisannya menyatakan bahawa setiap industri halal perlu mengaplikasikan sistem jaminan halal kerana ia sangat penting dalam pengawalan halal. Pengaplikasian sistem ini menurutnya tidak hanya tertumpu kepada pemprosesan mengikut standard halal semata-mata, malah turut melibatkan proses pembelian bahan ramuan dan keperluan yang berkaitan. Menurutnya juga, sistem ini boleh diadaptasi dalam sistem sedia ada seperti Hazard Analysis and Critical Control Point (HACCP) yang telah atau sedang diamalkan pihak industri dalam memastikan kehalalan produk yang dihasilkan.

Dalam memastikan pelaksaanan HAS ini berkesan, JAKIM telah mengeluarkan satu garis panduan dan menyerahkannya kepada industri untuk membangunkan sistem tersebut mengikut acuan industri. JAKIM tidak menetapkan bagaimana cara untuk melaksanakan sistem ini, tetapi mensyaratkan supaya kesemua elemen yang ditetapkan perlu diaplikasikan dalam sistem yang dibangunkan. Satu kajian yang dijalankan oleh Zurina Shafii dan Siti Noradibah Md Zain (2015: 1430-1438) tentang garis panduan yang dibekalkan telah merumuskan bahawa terdapat kekurangan pada garis panduan yang dikeluarkan oleh pihak JAKIM. Hal ini kerana bidang tugas dan tanggungjawab jawatankuasa halal tidak dinyatakan secara khusus dan kepada siapa perlu dibentangkan laporan jawatankuasa halal dalaman berkaitan penelitian pelaksanaan HAS. Di samping itu, garis panduan tersebut juga dilihat tidak lengkap kerana tidak menyatakan kewajipan untuk melantik penasihat syariah bagi menasihati jawatankuasa halal.

Dalam pelaksanaan HAS, antara eleman utama yang perlu diambil perhatian ialah mengenal pasti titik kritikal yang boleh menyumbang kepada konteminasi atau menjejaskan produk halal yang dihasilkan. Setiap titik kritikal yang dikenal pasti perlu diberi perhatian yang lebih, serta pengawalan yang ketat supaya rantaian pemprosesan berjalan mengikut garis panduan yang ditetapkan. Emi Normalina Omar et al. (2012: 4-5) dalam kajian mereka mendapati bahawa kejayaan mengenal pasti titik kritikal dalam rantaian pemprosesan sememangnya membawa kepada kejayaan pelaksanaan Halal Assurance System. Kenyataan ini turut disokong oleh kajian yang dijalankan Mohd Aliff Abdul Majid et al. (2015: 50-56) yang berpendapat bahawa pengawalan yang baik terhadap ancaman halal boleh menyumbang kepada kejayaan pelaksanaan sistem ini. Menurut mereka, pelaksanaan Sistem Jaminan Halal perlu mengambil kira tiga asas utama yang melibatkan setiap 
peringkat dalam rantaian pemprosesan. Asas tersebut dikenali sebagai zero's concept. Asas utama yang dimaksudkan ialah dengan mengelakkan daripada penggunaan sebarang bahan haram yang digunakan dalam pemprosesan. Asas yang kedua pula adalah tidak menghasilkan produk yang haram dan asas yang terakhir ialah tiada sebarang risiko yang diambil oleh pengusaha dalam pemprosesan. Menurut kajian tersebut, ketiga-tiga konsep ini mempunyai perkaitan dan menyumbang kepada kejayaan pelaksanaan HAS.

Walaupun terdapat kajian demi kajian yang telah dilakukan, namun sehingga hari ini masih belum ada kajian yang memfokuskan pelaksanaan HAS secara khusus dalam industri sembelihan. Justeru, penulis berpandangan bahawa kajian bagi menilai pelaksanaan HAS secara terperinci di rumahrumah sembelihan halal adalah perlu. Kajian yang dilakukan ini menumpukan kepada pemakaian industri terhadap garis panduan HAS yang dikeluarkan. Kajian ini turut mengkaji sumbangan pelaksanaan HAS kepada JAKIM dan juga industri sembelihan halal dalam setiap aspek khususnya dalam aspek pematuhan halal.

\section{Isu dan Cabaran dalam Pensijilan Halal}

Kajian sedia ada tentang isu-isu pensijilan halal amat penting sebagai asas untuk membantu penulis dalam menjalankan kajian berhubung isu dan cabaran dalam pelaksanaan HAS. Umum mengetahui bahawa pensijilan halal merupakan satu instrumen bagi industri untuk meyakinkan pengguna tentang produk yang dihasilkan. Paparan logo halal merupakan aspek utama yang diberikan perhatian oleh pengguna dalam mendapatkan sesuatu produk. Kesedaran yang tinggi akhir-akhir ini dalam kalangan pengguna mendorong industri untuk mendapatkan sijil halal. Produk yang memaparkan logo halal akan mendapat lebih sambutan berbanding produk tanpa logo halal (Siti Fatimah Hamidon, 2016).

Pensijilan halal tidak lekang dengan isu dan cabaran sehingga kini. Isu-isu ini ada kalanya mengganggu keyakinan pengguna. Kefahaman serta kesedaran adalah asas penting dalam menghadam dan menghadapi isu-isu yang timbul. Dalam meneliti isu ini, beberapa kajian telah dilakukan, antaranya berhubung kesedaran pengguna. Kajian dijalankan bagi menyelidik punca sebenar isu serta masalah yang timbul dan mengenal pasti hubungannya dengan kesedaran masyarakat hari ini. Zainalabidin Mohamad et al. (2008: 37-45) dalam kajian mereka mendapati bahawa rakyat Malaysia mempunyai kesedaran serta keyakinan yang tinggi terhadap sijil halal berasaskan beberapa faktor. Antara faktor tersebut ialah sosio ekonomi, keselamatan, penglibatan pihak kerajaan serta tahap kesedaran dan amalan dalam pengilangan. 
Kajian dalam aspek yang sama turut dijalankan oleh Golnaz Rezai et al. (2012: 33-42). Namun, mereka menegaskan bahawa keyakinan pengguna begitu tinggi hanya kepada logo halal Malaysia sahaja, manakala logo halal luar negara yang lain adalah sebaliknya. Tambahan lagi, mereka turut menekankan bahawa faktor lain yang menyumbang kepada keyakinan pengguna adalah faktor umur dan taraf pendidikan pengguna. Menurut Mustafa Afifi et al., keyakinan pengguna terhadap produk halal merupakan trend global yang bukan sahaja melibatkan pengguna Muslim, malah turut melibatkan pengguna bukan Muslim. Kesedaran ini adalah rentetan daripada penarafan global terhadap produk halal yang memenuhi aspek keselamatan dan jaminan kualiti (Musfata Afifi et al., 2014: 1176-1190).

Selain daripada kajian di atas, terdapat kajian terbaru yang dijalankan oleh Siti Fatimah Hamidon (2016) yang menggunakan survey sebagai kaedah utama dan temu bual sebagai kaedah sokongan. Bagi kaedah survey, seramai 100 orang responden telah dipilih untuk mewakili pengguna Muslim di kawasan Sungai Besar. Kajian yang dijalankan mendapati bahawa kesedaran pengguna di Sungai Besar Selangor terhadap isu halal masih di peringkat sederhana. Hal ini didorong oleh beberapa faktor, antaranya seperti maklumat yang kurang jelas berkaitan pensijilan halal, dan taraf pendidikan penduduk kawasan tersebut.

Antara isu lain yang turut dikaji adalah berkaitan dengan pengurusan pensijilan. JAKIM/JAIN dan MAIN adalah pihak berkuasa berautoriti yang dipertanggungjawabkan menguruskan Pensijilan Halal Malaysia. Dengan ini, pelbagai ragam pelanggan pensijilan halal sama ada dalam kalangan pengguna mahupun pemohon sijil halal akan dihadapi dalam menguruskan pensijilan halal. Perkhidmatan serta penyampaian yang bagus amatlah diharapkan oleh pelanggan dalam setiap urusan yang dilakukan. Walaupun begitu, Baizura Badruldin et al. (2012: 59-71) dalam kajiannya terhadap 547 pengusaha kecil dan sederhana mendapati pelanggan kurang berpuas hati dengan kualiti penyampaian yang diberikan pihak JAKIM dalam aspek komunikasi serta layanan yang diberikan. Kajian yang dilakukan menggunakan servqual gap analysis bagi menilai jurang antara harapan pengguna dan persepsi mereka terhadap perkhidmatan pihak JAKIM. Dapatan kajian ini perlu diberikan perhatian segera oleh pihak JAKIM bagi melancarkan proses pensijilan halal yang dilakukan. Kajian di atas turut disokong oleh Nurul Huda Nordin et al. (2009: 1-14) melalui kajiannya yang menegaskan bahawa terdapat kelemahan dalam proses pengurusan Pensijilan Halal Malaysia. Justeru, latihan komunikasi berkesan perlu diberikan serta JAKIM turut dicadangkan agar mempertingkatkan penyampaian perkhidmatan yang dilihat kurang memuaskan dalam kalangan pengguna. 
Selain daripada kajian-kajian di atas, Mustafa 'Afifi Ab. Halim dan Azlin Alisa Ahmad (2014: 9-14) turut menjalankan kajian berhubung aspek penyampaian pihak JAKIM. Kajian yang dijalankan mendapati bahawa kelemahan dalam aspek penyampaian oleh pihak JAKIM adalah berpunca daripada masalah kekurangan kakitangan. Kajian tersebut mencadangkan agar pihak kerajaan mengambil inisiatif serta memandang serius perkara ini kerana ia secara tidak langsung boleh menjejaskan imej institusi kerajaan. Perkara yang sama turut dibangkitkan dalam kajian yang dijalankan oleh Marliana Abdullah et al. (2015: 224-239) yang menyatakan bahawa kekurangan kakitangan merupakan antara faktor yang boleh menjejaskan proses pengeluaran sijil halal di Malaysia. Justeru, tindakan segera perlu diambil bagi memastikan kualiti penyampaian terhadap pengurusan pensijlan halal berjalan dengan baik dan memenuhi kehendak pengguna.

\section{KESIMPULAN}

HAS merupakan satu sistem kawalan dalaman yang baru diperkenalkan. Penguatkuasaannya baru melangkau tempoh lima tahun dalam industri. Berbekalkan garis panduan yang dikeluarkan, pihak industri diberi ruang untuk mencorak sendiri sistem ini mengikut keperluan masing-masing. Walau bagaimanapun, pelaksanaannya perlu memenuhi kriteria asas yang ditetapkan dalam garis panduan. Jika disoroti mutakhir ini, pensijilan halal dan isu berkaitan menjadi antara fokus pengkaji yang cenderung melakukan kajian dalam bidang ini. Namun, walaupun kajian demi kajian dilakukan dalam bidang ini, sehingga hari ini masih belum ada kajian yang menfokuskan pelaksanaan HAS secara khusus dalam industri sembelihan. Begitu juga kajian berkaitan isu-isu yang timbul dalam pelaksanaan HAS. Justeru, kajian ini mendapati bahawa masih terdapat lagi kelompongan dalam isu-isu pensijilan halal yang memerlukan kajian berterusan. Penulis berpandangan bahawa satu kajian perlu dilakukan bagi menilai pelaksanaan HAS secara terperinci di rumah-rumah sembelihan halal serta isu-isu yang timbul dalam pelaksanaan sistem ini. Dapatan daripada kajian yang dilakukan dilihat mampu membantu industri dalam melaksanakan HAS dan juga sebagai platform pemerkasaan serta penambahbaikan yang boleh dilakukan oleh pihak JAKIM. 


\section{RUJUKAN}

Ahmad Hidayat Buang \& Zulzaidi Mahmod (2012). "The Issues and Challenges of Halal Certification Bodies in Malaysia," Shariah Journal, vol. 20, no. 3, 271-288.

Baizura Badruldin, Zainalabidin Mohamed, Juwaidah Sharifuddin, Golnaz Rezai, Amin Mahir Abdullah, Ismail Abd Latif \& Mohd. Ghazali Mohayidin (2012). "Clients' Perception Towards JAKIM Service in Certification," Journal of Islamic Marketing, vol. 3, no. 1, 59-71.

Cerani, S., \& Bo, N. (2009). "Possibilities and Significance of the Implementation of Halal Assurance System (HAS) in Exixting Quality System in Food Industry," Biotechnology in Animal Husbandry, vol. 25, no. 3-4, 261-266.

Department of Islamic Development Malaysia (n.d.). The Malaysian Protocol for the Halal Meat and Poultry Productions. Kuala Lumpur: Department of Islamic Development Malaysia.

Department of Standards Malaysia (2009). Malaysia Standard, MS 1500 : 2009, Halal Food: Production, Preparation, Handling and Storage - General Guidelines (Second Revision). Malaysia: Department of Standards.

Emi Normalina Omar, Harlina Suzana Jaafar \& Muhamad Rahimi Osman (2012). "Assessing Halalan-Toyyiban Food Supply Chain in the Poultry Industry," International Halal Conference 2012 (INHAC) (2011), 4-5.

Golnaz Rezai, Zainalabidin Mohamed \& Mad Nasir Shamsudin (2012). “Assessment of Consumers' confidence on Halal Labelled Manufactured Food in Malaysia," Pertanika Journal of Social Science and Humanities, vol. 20, 1, 33-42.

Jabatan Kemajuan Islam Malaysia (2015). Manual Prosedur Pensijilan Halal Malaysia (Semakan ketiga) 2014. Kuala Lumpur: Jabatan Kemajuan Islam Malaysia.

Jafri Abdullah, Suhaimi Ab Rahman \& Zaidah Mohd Nor (2011). "Sembelihan Halal dalam Industri Makanan Halal," dalam Pengurusan Produk Halal di Malaysia, ed. Suhaimi Ab Rahman \& Jafri Abdullah. Serdang: Penerbit Universiti Putra Malaysia, 26-50.

Khadijah, Nakyinsige, Yaakob, B. Che Man, Awis \& Qurni Sazili (2012). "Comparing the Effect of Religious Slaughter without Stunning and Stunning on Carcass and Meat Quality," International Halal Conference 2012 (INHAC), Kuala Lumpur, 4-5 September 2012. 
Marco Tieman, Maznah Che Ghazali \& Jack G.A.J. van der Vorst (2013). "Consumer Perception on Halal Meat Logistics," British Food Journal, vol. 115, no. 8, 1112-1129.

Marliana Abdullah, Syaripah Nazirah Syed Ager, Nor 'Adha Abdul Hamid, Norazla Abdul Wahab, Wawarah Saidpudin, Surianom Miskam, Farah Mohd Shahwahid \& Norziah Othman (2015). "Isu dan Cabaran Pensijilan Halal: Satu Kajian Perbandingan Antara Malaysia dan Thailand," World Academic and Research Congress, Jakarta, 9-10 December 2015, 224239.

Mohd. Nazri Abdul Rahman \& Sharifudin Md. Shaarani (2012). "Study on the Effectiveness of Halal Certification in Slaughtering House Around Kota Kinabalu, Sabah," International Conference on Food Science and Nutrition, Kota Kinabalu, Sabah (April), 895-918.

Mohd Aliff Abdul Majid, Izhar Hafifi Zainal Abidin, Hayati Adilin Mohd Abd Majid \& Chemah Tamby Chik (2015). "Issues of Halal Food Implementation in Malaysia," Journal of Applied Environmental and Biological Sciences, vol. 5, 50-56.

MohdAl'Ikhsan Ghazali \& Siti Salwa Md. Sawari(2015). "Mengglobalisasikan Sistem Piawaian Standard Halal Malaysia di Peringkat Dunia," Sains Humanika, vol. 53, 2289-6996.

Mohd Al'Ikhsan Ghazali \& Siti Salwa Md. Sawari (2015). "Standard Piawaian Halal di Malaysia menurut Perundangan, Kelebihan dan Kekurangan," International Journal of Islamic and Civilizational Studies, vol. 2, 5661.

Muhamad Haziq Hassan, Sazelin Arif \& Safiah Sidek (2014). "Compliance with the Internal Halal Assurance System Among Food Service Operators in Melaka," Malaysia Special Issue Sci. Int. (Lahore), vol. 26, no. 4, 1553-1556.

Muhamad Haziq Hassan, Sazelin Arif \& Safiah Sidek (2015). "Knowledge and Practice for Implementing Internal Halal Assurance System among Halal Executives," Asian Social Science, vol. 11, 17), 57-66.

Mustafa 'Afifi Ab. Halim \& Azlin Alisa Ahmad (2014). "Enforcement of Consumer Protection Laws on Halal Products: Malaysian Experience," Asian Social Science, vol. 10, no. 3, 9-14.

Mustafa 'Afifi Ab. Halim, Mohd Mahyeddin Mohd Salleh, Mohd Izhar Ariff Mohd Kashim, Azlin Alisa Ahmad \& Norhaslinda Nordin (2014). "Halal Pharmaceuticals: Legal, Shari'ah Issues and Fatwa of Drug, Gelatine and Alcohol Contribution/Originality," International Journal of Asian Social Science, vol. 4, no. 412, 1176-1190. 
Nurulhuda Noordin, Nor Laila Md Noor, Mardziah Hashim \& Zainal Samicho (2009). "Value Chain of Halal Certification System: A Case of The Malaysia Halal Industry Nurulhuda Noordin," European and Mediterranean Conference on Information Systems (EMCIS), Crown Plaza Hotel, 2009.

Pazim Othman, Irfan Sungkar \& Wan Sabri Wan Hussin (2009). "Malaysia as an International Halal Food Hub: Competitiveness and Potential of Meat-based Industries," Asean Economic Bulletin, vol. 26, no. 3, 306320.

Petracci, M., Bianchi, M., \& Cavani, C. (2010). "Pre-slaughter Handling and Slaughtering Factors Influencing Poultry Product Quality," World's Poultry Science Journal, vol. 66, no. 1, 17-26.

Siti Fatimah Hamidon (2016). "Pandangan Pengguna Muslim Terhadap Pemakaian Logo Halal JAKIM: Kajian di Sungai Besar, Selangor," (Tesis Sarjana, Akademi Pengajian Islam, Jabatan Syariah dan Undangundang, Universiti Malaya, Kuala Lumpur).

Suhaimi Ab Rahman, Zulaipa Ruzulan \& Muhammad Shahrim Abdul Karim (2014). "Development of Islamic Law: The Application of ' Urf in Halal Animal Slaughtering Practices," Sains Humanika, vol. 1, 11-17.

Syed Ghazaly Alqudsi (2014). "Awareness and Demand for 100\% Halal Supply Chain Meat Products," Procedia-Social and Behavioral Sciences, vol. 130, 167-178.

Zainalabidin Mohamed, Golnaz Rezai \& Mad Nasir Shamsudin, E. C. F. C. (2008). "Halal Logo and Consumers' confidence: What are the Important Factors?" Economic and Technology Management Review, vol. 3, 37-45.

Zalina Zakaria \& Siti Zubaidah Ismail (2015). "The Development of Regulations Concerning Halal through Trade Description Act 2011 in Malaysia," Shariah Journal, vol. 23, no. 2, 189-216.

Zalina Zakaria (2015). "Regulation of Cosmetics: What Has Malaysia Learnt from the European System?," Journal Consumer Policy, vol. 38, 39-59.

Zurina Shafii \& Siti Noradibah Md Zain (2015). "Halal Assurance Mechanisms in Halal Industry: An Appraisal on Its Effectiveness Towards Continuous Halal Assurance and the Way Forward," 2nd International Conference of Education and Social Sciences (INTCESS15), Istanbul, Turkey, (February), 1430-1438. 


\section{Senarai Temu bual}

Muhammad Hawari Hassan (Penolong Pengarah Kanan, Bahagian Hub Halal JAKIM), dalam temu bual bersama penulis pada 23 Mei 2017.

Mohd Amri Abdullah (Penolong Pengarah Kanan, Bahagian Hub Halal JAKIM), dalam temu bual bersama penulis pada 27 Januari 2018.

Asmawaty@Siti Asmah Ahmad (Ketua Unit Persijilan, Bahagian Pengurusan Halal, Jabatan Agama Islam Sarawak), dalam temu bual bersama penulis pada 29 Januari 2018. 